\title{
STRUCTURE OF LARK SPARROW SONG IN CALIFORNIA
}

\author{
EDWARD R. PANDOLFINO, 1328 49th Street, Sacramento, California 95819; \\ erpfromca@aol.com \\ RICHARD W. HEDLEY, Department of Biological Sciences, University of Alberta, \\ 116 St. \& 85 Ave., Edmonton, Alberta T6G 2R3, Canada
}

ABSTRACT: We studied the song of the Lark Sparrow (Chondestes grammacus) in recordings of 15 individuals from a variety of locations in California. Lark Sparrow song is delivered as variable sequences structured in a hierarchy of four levels: elements, syllables, strophes, and themes. At the simplest level, elements can be distinguished by their appearance on a spectrogram. Birds vary the number of repetitions of each element to produce a syllable and string together several syllables to produce a strophe (mean 5.9 syllables per strophe). Strophes are delivered at an average rate of 5.4 per minute. Strophes can be further classified as belonging to one of a few themes in a male's repertoire, where strophes in different themes are composed of almost entirely distinct elements and syllables. In $<6 \%$ of strophes did we find elements from one theme mixed with elements from a different theme. Each individual sang one to three themes. The size of the repertoire of strophes is large but we could not quantify it because within a continuous bout of singing any particular sequence of syllables was repeated in only $5 \%$ of strophes. Each theme comprised roughly 20-40 distinct syllables. Thus an individual singing three themes could have a repertoire of 60-120 syllables. The number of unique elements per theme ranged from 11 in birds revealing just one theme up to 39 in birds revealing three themes, but longer recordings may have yielded more elements per bird. If our observations for single-themed birds may be extrapolated, birds with three themes might have repertoires of 33-51 elements. In the two comparisons possible, we detected almost no sharing of elements among neighboring birds.

One of the most fascinating aspects of bird behavior is the remarkable range in size of the song repertoire among different species of songbirds (Kroodsma 2005, Catchpole and Slater 2008, Pieplow 2017). Individuals of many species, such as the Chipping Sparrow (Spizella passerina; Borror 1959), Ovenbird (Seiurus aurocapilla; Lein 1981), and Zebra Finch (Taeniopygia guttata; Catchpole and Slater 2008), get by with a single simple primary song that varies little. Others, such as the White-crowned Sparrow 
(Zonotrichia leucophrys; Baptista 1975), may have a slightly more complex song, but also with almost no variation. Many birds use a few to perhaps a dozen different songs. Examples include the Great Tit (Parus major; Krebs et al. 1978), Hermit Thrush (Catharus guttatus; Borror 1964), and Song Sparrow (Melospiza melodia; Borror 1965, Hiebert et al. 1989). Still others, such as some thrashers, may have hundreds or even thousands of different songs (Kroodsma 2005).

We also see very different means of producing variety. In some birds each successive song differs (immediate variety), whereas others repeat the same song several times before switching to a new song type (eventual variety). Song diversity may be achieved by using many separate elements, including some appropriated from other birds, as in the songs of the Northern Mockingbird (Mimus polyglottos; Farnsworth et al. 2011). Other birds, such as the Great Reed Warbler (Acrocephalus arundinaceus; Catchpole and Slater 2008), may use fewer elements but vary the organization of those elements within each song. Some birds create further diversity by organizing their repertoires into themes. Themes are subsets of the repertoire characterized by high rates of transitions among elements within the theme, followed by infrequent, often abrupt, transitions to another theme. Such organization by themes has been demonstrated in the Nightingale (Luscinia megarhynchos; Todt and Hultsch 1998, Weiss et al. 2014), California Thrasher (Toxostoma redivivum; Sasahara et al. 2012), and Cassin's Vireo (Vireo cassinii; Hedley 2016).

The structure of the song of the Lark Sparrow (Chondestes grammacus), while not well studied, has been described as "trills and sweet notes interrupted by a rather unmelodious churr" (Hoffmann 1927), "a melodious jumble of rich notes and trills ranging in pitch and volume and interspersed with rather unmelodious harsh buzzes or churrs" (Martin and Parrish 2000), "a rapid jumble of trills, sweet notes, and musical warbles" (Beedy and Pandolfino 2013), and "a series of rich, melodious notes and trills and unmusical buzzes" (Dunn and Alderfer 2017). Pieplow (2017) described the general structure as, "consecutive songs usually different, often with many of the same components rearranged." Borror (1961) grouped the Lark Sparrow with other birds showing much intraspecific variation and noted 58 different patterns in a single individual. He also found no examples of individuals sharing a song pattern.

The Lark Sparrow is distinctive among North American sparrows (family Passerellidae). The only member of its genus, it is more boldly marked than most other sparrows, and it reportedly engages in courtship displays more elaborate and complex than those of any other member of this family (Martin and Parrish 2000). We chose to examine the Lark Sparrow's song because of the lack of detailed information about its structure and repertoire size. We also wanted to determine if the Lark Sparrow's song structure is similar to that of other species, and whether similarities in behavior or close taxonomic relationships might be linked to similar song structures. We used recordings made in the breeding season at multiple locations in California to analyze variations in and the structure of individual Lark Sparrow songs. 


\section{METHODS}

\section{Terminology}

Since authors use a variety of terms to describe parts of bird song (phrase, syllable, element, etc.) in different ways, it is important to specify how one is using such terms for any given analysis. In this case, we follow the terminology suggested by Catchpole and Slater (2008) for terms such as element, syllable, and strophe. Figure 1 shows how we applied these terms for our analyses. An element was the simplest subunit of song, typically appearing as a continuous trace on a spectrogram. We identified each unique element in a given recording on the basis of frequency, range of frequencies, duration, and shape, and assigned it a letter. These features were highly stereotyped within each individual's repertoire, enabling us to consistently identify each element visually (Appendix 1; www.westernfieldornithologists.org/V50A/ LarkSpAp1.pdf). A syllable was a repetition of the same element one or more times. We identified syllables with a combination of a letter and a number, the letter signifying the element constituting the syllable, the number signifying the number of times that element was repeated (e.g., syllable B6 in Figure 2 indicates that the syllable consists of six repetitions of element $\mathrm{B}$; in the third strophe syllable B5 comprises five repetitions of element B). A strophe is a string of several syllables in quick succession. Consecutive strophes were easily distinguished because the interval of silence between elements and syllables within a strophe was typically less than 0.2 seconds, while the gap between strophes was on the order of several seconds. We

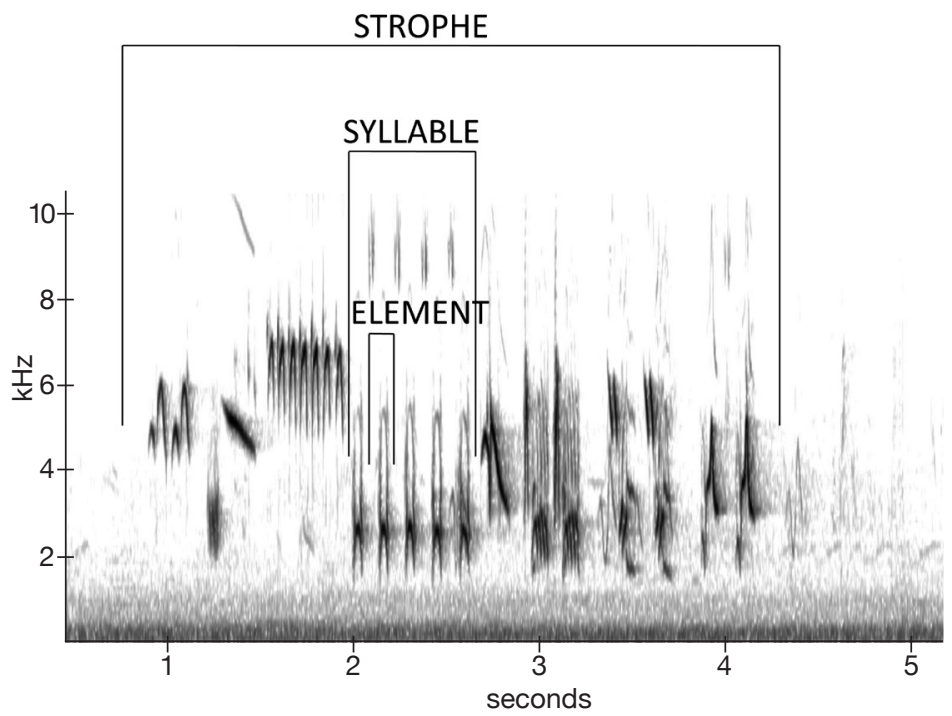

Figure 1. Sample spectrogram of Lark Sparrow illustrating the terminology used for the three lower levels of the four-level hierarchy. 

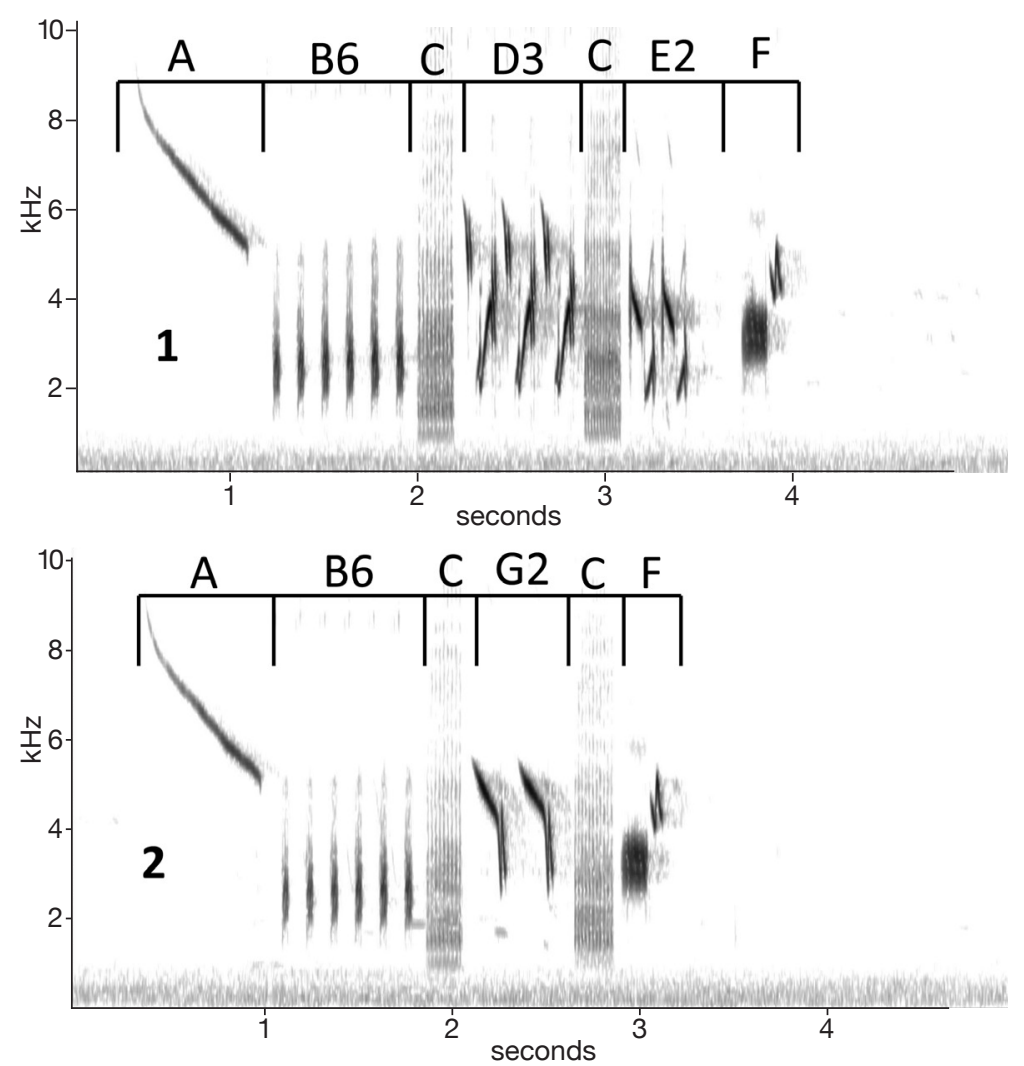

Figure 2. Spectrograms of the first four strophes from recording XC416410. Letters signify elements, and numbers indicate the number of repetitions of an element to produce a syllable (e.g., B6 is a syllable comprising six repetitions of element B). Elements may recur in consecutive strophes (e.g., element $B$ in each strophe), but the composition and order of elements varies from strophe to strophe (parts 3 and 4 on page 62).

chose to use the term strophe, instead of song type, because this term better suggests the wide variation of these subunits in the Lark Sparrow. Figure 2 shows four consecutive strophes of a Lark Sparrow song with the distinct elements and syllables labeled.

We defined themes post hoc after observing that an individual's repertoire could be categorized into up to three subsets that consistently appeared together in sequence (see Results). To confirm the objectivity of these themes, we used the community-clustering algorithm for detecting communities in transition networks described by Pons and Latapy (2006), which we implemented by using the function cluster_walktrap in the program igraph (Csárdi and Nepusz 2006) in R version 3.4.2 (R Core Team 2016). We then compared the results of clustering with the results of our 

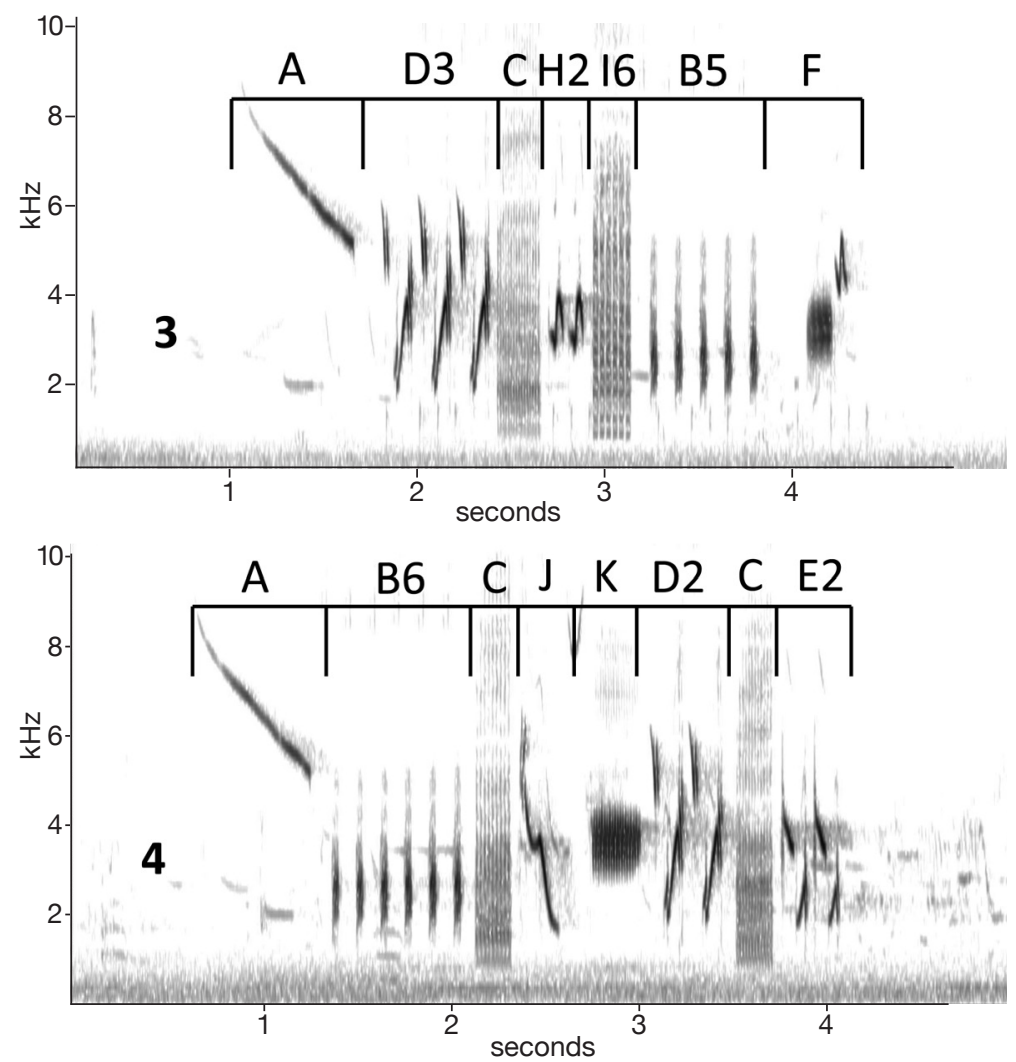

Figure 2 (continued).

subjective assessment of themes for all individuals in whose repertoire we identified more than one theme. Further details can be found in Appendix 2 (www.westernfieldornithologists.org/V50A/LarkSpAp2.pdf).

\section{Recordings}

We used all recordings from our personal collections, from the Macaulay Library (www.macaulaylibrary.org), or from www.xeno-canto.org that were made in California during the breeding season (Figure 3; Table 1) and included at least 12 consecutive strophes and were of good quality (signalto-noise ratio of approximately 5:1 or better). In total, our dataset included songs from fifteen individuals. Recording numbers beginning with ML are from the Macaulay Library, those beginning with XC are from Xeno-Canto. The other two recordings are available at www.westernfieldornithologists. org/archive/V50/LarkSpAp3. If there were pauses during a bout of singing, we used subsequent singing only if we were certain it came from the 


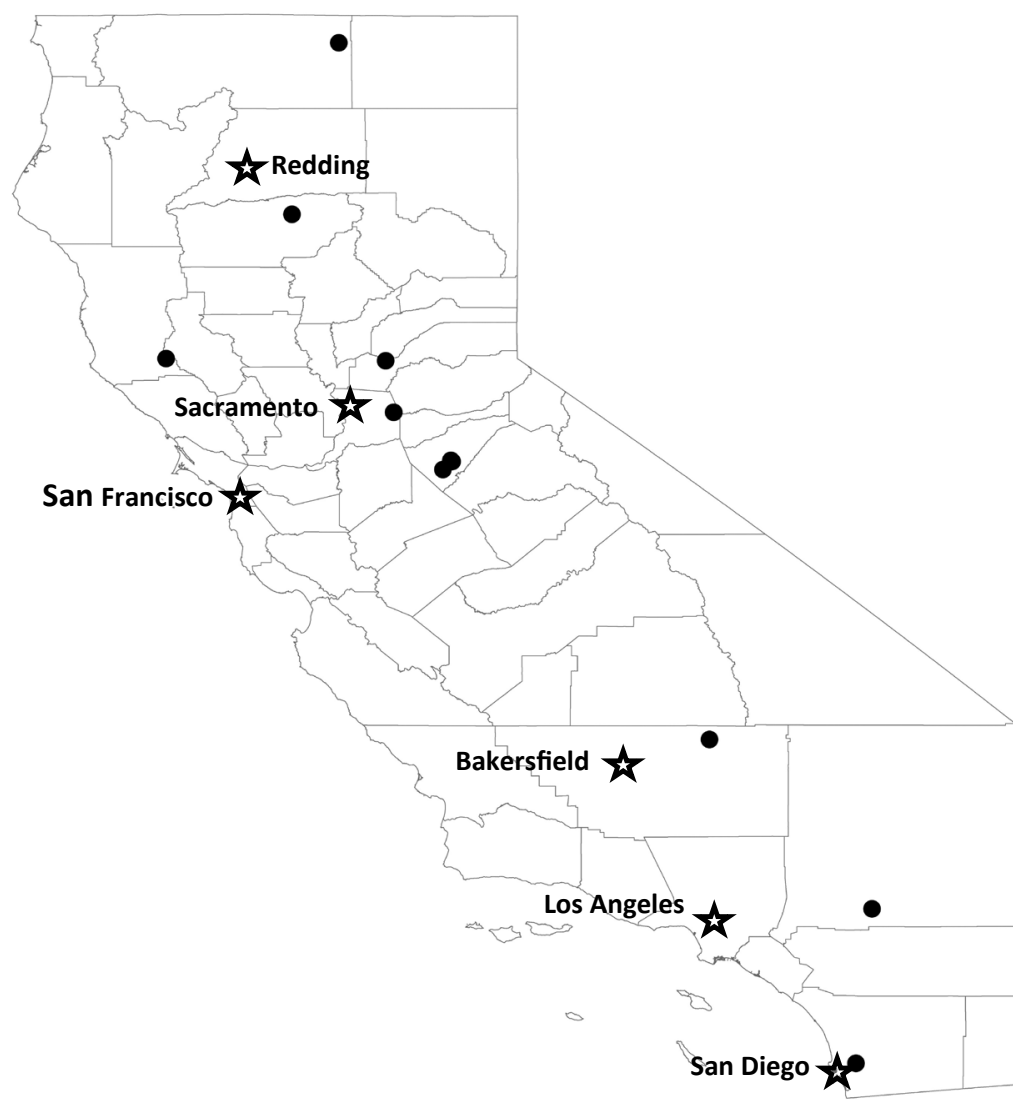

Figure 3. Locations of recordings of the Lark Sparrow analyzed from California.

same individual. Because the individuals recorded were not marked, it was not possible to obtain very large numbers of strophes from any single bird.

We used the software Raven (Cornell Laboratory of Ornithology) to make spectrograms and used printouts of all strophes to identify elements and analyze structure. Appendix 1 (www.westernfieldornithologists.org/V50A/ LarkSpAp1.pdf) includes spectrograms of all strophes and the assignments of elements and syllables used for every recording.

\section{RESULTS}

Each strophe of a Lark Sparrow song typically consisted of 5-8 syllables (Table 2). Strophes averaged 2.7 seconds in length (range 2.2-3.5) and were given at an average rate of 5.4 per minute (range 3.5-12.1). Note that the most rapid song (12.1 strophes/min) was an outlier, as the rate in the next 


\section{STRUCTURE OF LARK SPARROW SONG IN CALIFORNIA}

Table 1 Metadata for Recordings of Lark Sparrow Songs Analyzed

\begin{tabular}{lccccc}
\hline Recording $^{a}$ & Latitude & Longitude & Date & Time $^{b}$ & Recordist \\
\hline MTRP_3-26-17 & 32.84 & -117.04 & 26 Mar 2017 & 07:25 (dawn +41) & B. Rideout \\
MTRP_6-25-16 & 32.84 & -117.04 & 25 Jun 2016 & 07:05 (dawn +83) & B. Rideout \\
ML118851 & 39.00 & -123.07 & 22 May 2001 & 07:21 (dawn +86) & G. Keller \\
ML22963 & 35.67 & -118.32 & 16 May 1994 & ? & W. Fish \\
ML56920 & 41.76 & -121.56 & 2 Jun 1991 & 09:50 (dawn +253) & G. Keller \\
XC125433-30 & 34.19 & -116.90 & 3 Jun 2001 & $07: 00($ dawn +82) & R. Webster \\
XC171192 & 38.53 & -121.08 & 24 Mar 2014 & $06: 40($ dawn -23) & E. Pandolfino \\
XC416403 & 38.53 & -121.08 & 2 Apr 2017 & $06: 47($ dawn -2) & E. Pandolfino \\
XC416405 & 38.53 & -121.08 & 4 May 2017 & $07: 32($ dawn +87) & E. Pandolfino \\
XC416410 & 40.26 & -121.97 & 9 Apr 2015 & $07: 36($ dawn +57) & E. Pandolfino \\
XC416413 & 38.98 & -121.15 & 21 Apr 2017 & $07: 50($ dawn +90) & E. Pandolfino \\
XC416416 & 38.03 & -120.65 & 20 Apr 2018 & $06: 41($ dawn +32) & E. Pandolfino \\
XC416511 & 38.11 & -120.58 & 20 Apr 2018 & $08: 28($ dawn +139) & E. Pandolfino \\
XC416515 & 38.11 & -120.58 & 20 Apr 2018 & $08: 43($ dawn +154) & E. Pandolfino \\
XC416519 & 38.10 & -120.57 & 20 Apr 2018 & $09: 33($ dawn +204) & E. Pandolfino \\
\hline
\end{tabular}

${ }^{a}$ Each recording represents one individual.

${ }^{b}$ Number of minutes before (negative) or after local dawn in parentheses.

most rapid song was 6.6 per minute. That outlier song (XC171192) was recorded 23 minutes before dawn, earlier than any other recording used.

Each syllable was composed of one or more repetitions of the same element, and variation in consecutive strophes was generated by use of different elements, altering the order of the syllables, or varying the number of repetitions of an element in a syllable. For some individuals, additional variation in strophe composition was further enhanced by multiple distinct

Table 2 Numbers and Ratios of Components of Lark Sparrow Song by Its Four Levels of Hierarchy

\begin{tabular}{lccccccc}
\hline & & & \multicolumn{5}{c}{ Elements/theme } \\
Recording & Strophes & Themes & Elements & $1^{a}$ & $2^{a}$ & $3^{a}$ & Syllables/strophe \\
\hline MTRP_3-26-17 & 20 & 1 & 11 & 11 & & & 6.4 \\
MTRP_6-25-16 & 25 & 2 & 22 & 13 & 9 & & 6.4 \\
ML118851 & 14 & 2 & 24 & 11 & 13 & & 6.9 \\
ML22963 & 36 & 2 & 27 & 13 & 14 & & 7.0 \\
ML56920 & 13 & 2 & 23 & 10 & 13 & & 5.2 \\
XC125433-30 & 51 & 3 & 27 & 9 & 10 & 8 & 5.5 \\
XC171192 & 41 & 1 & 11 & 11 & & & 5.5 \\
XC416403 & 26 & 2 & 22 & 11 & 11 & & 5.5 \\
XC416405 & 38 & 2 & 25 & 11 & 14 & & 7.3 \\
XC416410 & 17 & 1 & 14 & 14 & & & 7.6 \\
XC416413 & 18 & 2 & 17 & 12 & 6 & & 5.4 \\
XC416416 & 29 & 2 & 26 & 13 & 13 & & 5.6 \\
XC416511 & 17 & 1 & 13 & 13 & & & 5.6 \\
XC416515 & 38 & 1 & 17 & 17 & & & 5.2 \\
XC416519 & 51 & 3 & 39 & 16 & 12 & 11 & 5.0 \\
\hline
\end{tabular}

${ }^{a}$ Number of themes evident in the recording. 
sets of elements (themes). Transitions between themes were abrupt: themes did not grade into one another but were temporally distinct. A given individual might sing a few or many strophes by using elements from one theme before switching to another theme (Table 3, Figure 4). In our sample, individual birds sang one to three distinct themes, each theme consisting of as many as 17 different elements (Table 2). Five birds revealed one theme, eight birds revealed two themes, and two birds revealed three themes. It is likely that some birds would have revealed more themes had longer recordings been available. We found a nonsignificant positive correlation between the number of strophes recorded and the number of themes observed $(n=15, r=0.46$, $p=0.09$ ). Our subjective classification of themes agreed with the result of the more objective community-clustering algorithm. The two methods produced identical results for seven of ten individuals that sang more than one

Table 3 Detailed Structure of a Sample Lark Sparrow Song Consisting of Two Themes (XC416416)

\begin{tabular}{|c|c|c|c|c|c|c|c|c|}
\hline \multirow{2}{*}{$\begin{array}{l}\text { Strophe and theme } \\
\text { Theme } 1\end{array}$} & \multicolumn{8}{|c|}{ Syllables and elements } \\
\hline & & & & & & & & \\
\hline 1 & A & B & $\mathrm{C}$ & D6 & E6 & & & \\
\hline 2 & C & F5 & A & E6 & G2 & $\mathrm{H}$ & $\mathrm{I} 2$ & $\mathrm{~J}$ \\
\hline 3 & C & F5 & A & E6 & G3 & & & \\
\hline 4 & A & $\mathrm{H} 2$ & K9 & $\mathrm{F} 4$ & G3 & I3 & & \\
\hline 5 & C & F5 & E7 & L4 & & & & \\
\hline 6 & B & A & $\mathrm{C}$ & D5 & & & & \\
\hline 7 & C & E7 & G4 & $\mathrm{H} 2$ & A & I2 & & \\
\hline 8 & C & F5 & A & E6 & G2 & & & \\
\hline 9 & A & $\mathrm{B}$ & $\mathrm{C}$ & D6 & E5 & & & \\
\hline 10 & C & $\mathrm{J}$ & $\mathrm{H} 2$ & L4 & F5 & & & \\
\hline 11 & C & F5 & A & E7 & I4 & K7 & & \\
\hline 12 & $\mathrm{~J}$ & $\mathrm{~B}$ & A & M & $\mathrm{C}$ & D6 & & \\
\hline 13 & A & $\mathrm{H} 2$ & F5 & $\mathrm{C}$ & G4 & E6 & $\mathrm{I} 2$ & \\
\hline 14 & C & F5 & G3 & E6 & A & $\mathrm{I} 2$ & K8 & \\
\hline 15 & M & A & D5 & L3 & & & & \\
\hline \multicolumn{9}{|l|}{ Switch to theme 2} \\
\hline 16 & $\mathrm{~N}$ & $\mathrm{O}$ & $\mathrm{P}$ & Q4 & $\mathrm{R} 4$ & S5 & T3 & \\
\hline 17 & $\mathrm{U}$ & S5 & $\mathrm{R} 4$ & Q3 & $\mathrm{T} 2$ & & & \\
\hline 18 & $\mathrm{~N}$ & $\mathrm{P}$ & $\mathrm{V}$ & $\mathrm{W}$ & $\mathrm{T} 2$ & X3 & Y4 & \\
\hline 19 & $\mathrm{O}$ & $\mathrm{Z3}$ & Q3 & & & & & \\
\hline 20 & $\mathrm{~N}$ & $\mathrm{P}$ & $\mathrm{V}$ & $\mathrm{W}$ & $\mathrm{R} 5$ & S4 & & \\
\hline 21 & $\mathrm{U}$ & S5 & $\mathrm{R} 4$ & $\mathrm{Q}$ & $\mathrm{O}$ & Z3 & & \\
\hline 22 & W & $\mathrm{V}$ & T2 & Y4 & $\mathrm{O}$ & X3 & & \\
\hline 23 & $\mathrm{U}$ & $\mathrm{O}$ & $\mathrm{P}$ & Q3 & T3 & Y4 & & \\
\hline 24 & $\mathrm{U}$ & S5 & R6 & & & & & \\
\hline 25 & $\mathrm{U}$ & S5 & $\mathrm{R} 5$ & W & V & & & \\
\hline \multicolumn{9}{|c|}{ Switch back to theme 1} \\
\hline 26 & A & M & $\mathrm{C}$ & D5 & E4 & & & \\
\hline 27 & $\mathrm{~J}$ & B2 & $\mathrm{C}$ & F5 & A & E5 & & \\
\hline 28 & A & $\mathrm{C}$ & $\mathrm{I} 2$ & $\mathrm{~F} 4$ & A & E3 & & \\
\hline 29 & A & $\mathrm{H} 2$ & $\mathrm{~B}$ & $\mathrm{C}$ & D5 & L3 & $\mathrm{J}$ & \\
\hline
\end{tabular}




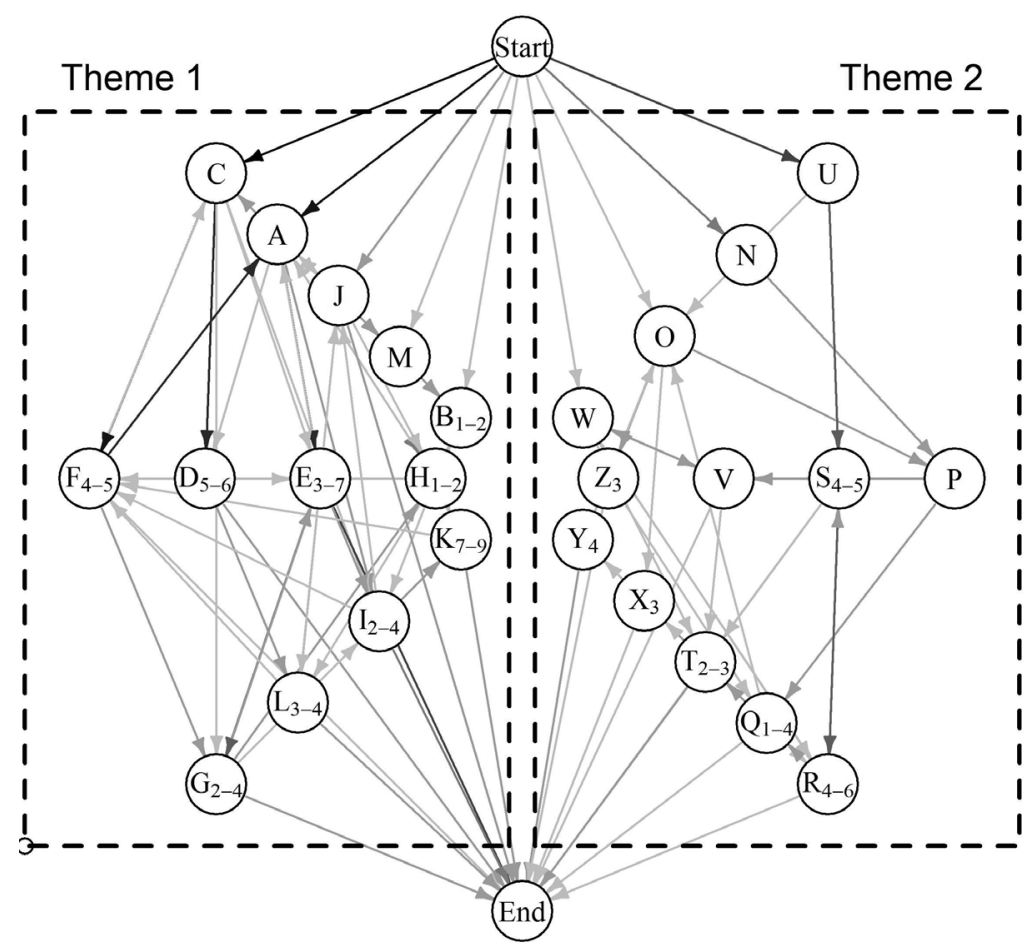

Figure 4. A network representation of the transitions between elements in a typical two-themed song of a Lark Sparrow (XC416416, Table 3) consisting of 29 strophes. The first set of 15 strophes uses 14 different elements (A through $\mathrm{M}$; theme 1), the next set of 10 strophes uses 13 elements ( $\mathrm{N}$ through $\mathrm{Z}$; theme 2), and the last set of 4 strophes revert back to elements from theme 1 (A through $\mathrm{M}$ ). To improve clarity, repetitions of the same element are not shown (e.g., syllables G2 and G3 are both included as element G). Darker arrows signify more frequent transitions (1 to 8 instances). Themes 1 and 2 are completely separated, with complex transitions within each theme and no transitions between the themes.

theme and 75-96\% agreement for the other three individuals (Appendix 2). This concordance supports our conclusion that organization by themes is a genuine characteristic of the Lark Sparrow's song.

With few exceptions, song structure conformed largely to a specific set of rules:

1. Distinct strophes typically differ in structure (i.e., composition and order of syllables). Of 433 strophes observed, only $22(5 \%)$ were repeated within a recording.

2. Although elements are often repeated within a syllable, elements are very rarely repeated in two or more syllables in a single strophe. Of the 433 strophes, only 15 (3\%) used any element in more than one syllable. 
3. Elements from one theme are rarely used in other themes. Of the 300 strophes observed in the songs of the ten birds that revealed more than one theme, only 17 (6\%) included an element that occurred in two or three themes. The actual number of such occurrences may even be lower as 9 of the 17 apparent repetitions involved buzzy, polyphonic elements (e.g., element C in Figure 2), which are difficult to classify and may have variations difficult to detect in a spectrogram. If one eliminates those cases, we observed only 8 examples of elements from one theme appearing in another (3\%).

Since strophes with the exact same structure were so rare, it was impossible with the sample size available to us to estimate repertoire size at the level of the strophe. Given the variety of elements used, the varying number of repetitions of elements per syllable, variations in the order of syllables, and the use of multiple themes, the potential size of the strophe repertoire is huge. We attempted to estimate repertoire size at the syllable level (Figure 5) by plotting the number of unique syllables vs. the total number of syllables sung. Of birds that revealed only one theme, all individuals appeared to have neared a maximum. For example, in recording XC416515, only six out of $36(17 \%)$ were introduced in the final $50 \%$ of the recording, only one $(3 \%)$ in the final $25 \%$ of the recording. The rate of accumulation of syllables among the birds revealing two or three themes suggested that longer recordings of all would yield more unique syllables. It is also possible that longer recordings might reveal additional themes. Taken together, these results suggest that each theme may contain 20-40 unique syllables, yielding a total repertoire of 60-120 syllables for a bird with three themes.

We also examined repertoire size at the level of the element (Figure 6). Among the three individuals whose songs consisted of only a single theme, the number of unique elements reached a maximum, ranging from 11 to 17 . For birds revealing two or three themes, only two (XC416416: 2 themes, 26 elements and XC125433-30: 3 themes, 27 elements) might have reached a maximum. The range of unique elements observed was 18-27 for birds with two themes and 27-39 for birds with three themes. As noted above for syllable repertoire, longer recordings might have revealed additional themes.

On the basis of a very limited sample, neighboring Lark Sparrows seem to share very few elements. Recordings XC416511 (one theme, 13 elements), XC416515 (one theme, 17 elements), and XC416519 (three themes, 39 elements) were recorded on the same day within an area of diameter 500 m. Recordings XC415511 and XC 416515 include only two shared elements. Recording XC416519 includes no elements shared with the other two birds. Additionally, recordings XC416403 (two themes, 22 elements) and XC416405 (two themes, 25 elements) were made approximately 800 $\mathrm{m}$ apart, and these birds' songs shared no elements.

\section{DISCUSSION}

As noted above, the Lark Sparrow is unusual for its family in several ways. The size and structure of its song repertoire are also unusual among the sparrows. In general, sparrows' song repertoires are small, ranging from one or a few song types in the genera Spizella and Zonotrichia (Pieplow 2017) to 
perhaps as many as 40 for the Bachman's Sparrow (Peucaea aestivalis; Borror 1971). The Vesper Sparrow (Pooecetes gramineus) is an exception and may have a repertoire as large and a structure as complex as the Lark Sparrow's (Kroodsma 1972). Vesper Sparrows use at least 40 different elements that are rearranged to produce a very large song repertoire (Kroodsma 1972, Pieplow 2017). Interestingly, the Vesper Sparrow was once considered the Lark Sparrow's closest relative (Patten and Fugate 1998). Genetic analysis, however, suggests that the Lark Bunting (Calamospiza melanocorys) is the Lark Sparrow's closest relative (Carson and Spicer 2003). Lark Buntings also sing songs composed of a set of distinct elements, but the elements and order in which they are uttered are relatively stereotyped and individuals generally have only one or a few song types (Shane 2000, Pieplow 2017). Stillwell and Stillwell (1955) detected 11 "phrase types" (analogous to syllables as we have defined them) in songs of two individuals. In contrast to the complex, multi-step pre-copulatory courtship displays of the Lark Sparrow, the courtship displays of the Vesper Sparrow and Lark Bunting are much simpler. Male Vesper Sparrows may strut briefly before a female, sometimes displaying and singing briefly in flight (Berger 1968). The Lark Bunting is well-known for dramatic flight-song displays, which may be repeated many times in the presence of a female, but copulation occurs with little further fanfare (Shane 2000). Thus neither the Vesper Sparrow, with a fairly similar song structure, nor the closely related Lark Bunting has courtship behavior as complex as the Lark Sparrow's.

In the simplest sense, birds build large song repertoires by two structural methods. Some, such as the thrashers of the genus Toxostoma, produce variety mainly through use of a very large number of elements (Sheppard 2018, Pieplow 2017). Others, such as the Sedge Warbler (Acrocephalus schoenobaenus; Catchpole 1976) and Rose-breasted Grosbeak (Pheucticus ludovicianus; Lemon and Chatfield 1973) employ a relatively small number of discrete elements which are grouped and rearranged to produce remarkable variety in their songs. The Lark Sparrow's song structure clearly falls into the latter category. It also appears that the order of delivery of song elements is nonrandom and that transitions within certain subsets of the repertoire (themes) are clearly favored. Other species known to organize their songs according to themes include the Black-capped (Vireo atricapilla; Gryzbowski 1995) and Cassin's (Hedley 2016) Vireos and the Rock Wren (Salpinctes obsoletus; Kroodsma 1975). Even highly complex songs that may appear to be a random succession of elements, such as those of the Nightingale (Weiss et al. 2014) and California Thrasher (Sasahara et al. 2012), have revealed some degree of theme-based organization when subjected to detailed network analysis (Watts and Strogatz 1998). What may set the Lark Sparrow apart is how strictly it adheres to the use of discrete themes, with very little mixing of elements between themes.

Large, complex song repertoires have been correlated with mating success in many species (Catchpole and Slater 2008). Pairing and mating earlier in the breeding season have been linked to larger repertoires in the Northern Mockingbird (Howard 1974) and Sedge Warbler (Acrocephalus schoenobaenus; Catchpole 1980). In the Great Tit (Lambrechts and Dhondt 1986), Great Reed Warbler (Catchpole 1986), and Song Sparrow (Hiebert et al. 1989, 


\section{STRUCTURE OF LARK SPARROW SONG IN CALIFORNIA}
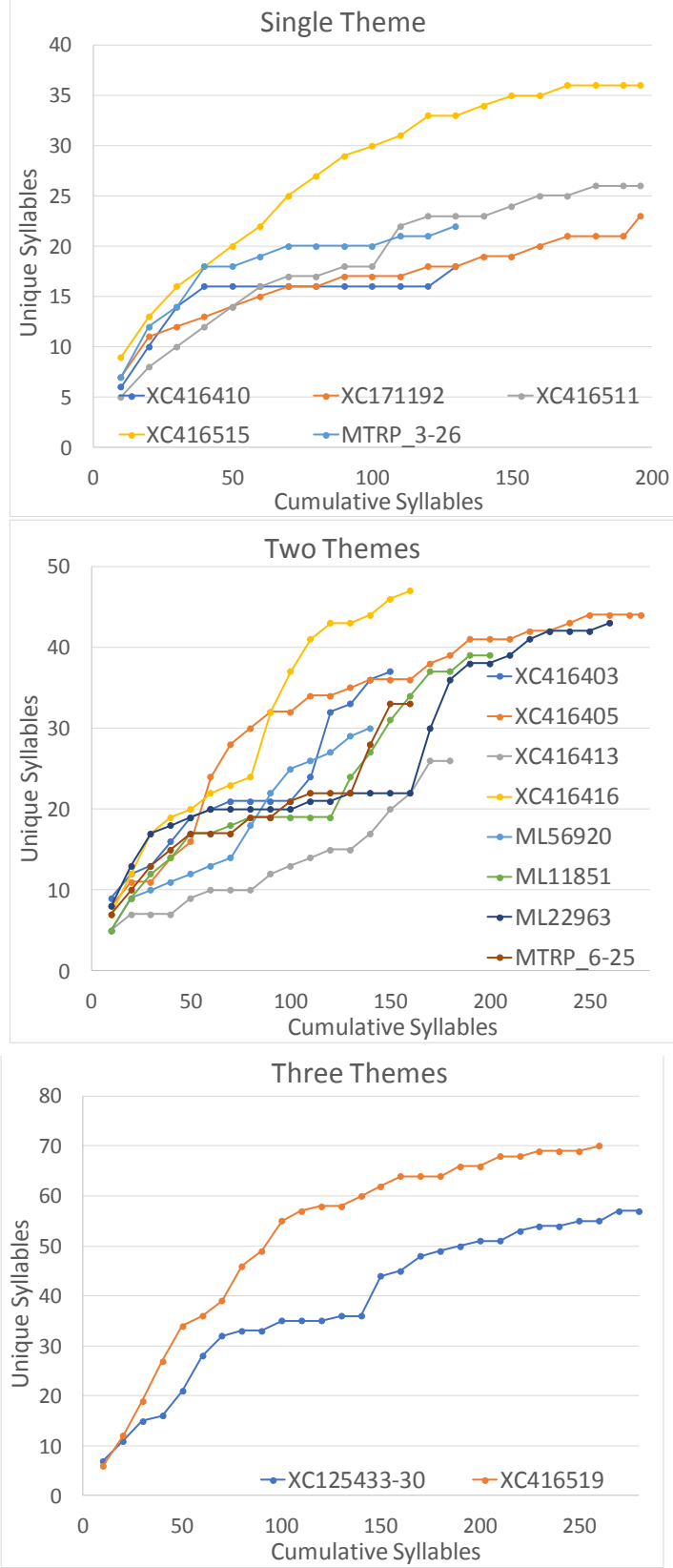

Figure 5. Accumulation of syllable variety with the total number of syllables delivered in recordings of Lark Sparrow song, by number of themes. 


\section{STRUCTURE OF LARK SPARROW SONG IN CALIFORNIA}
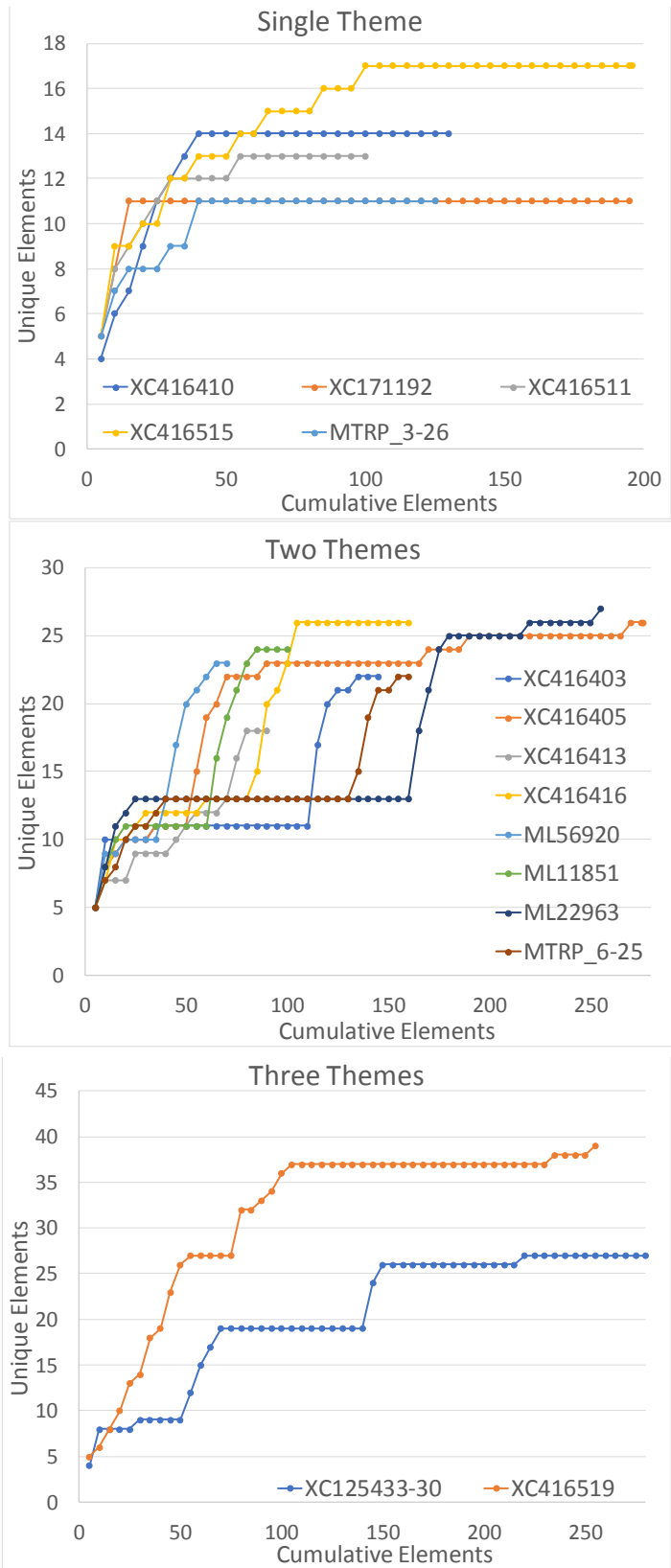

Figure 6. Accumulation of element variety with the total number of elements delivered, in recordings of Lark Sparrow song, by number of themes. 
Potvin et al. 2015) repertoire size and overall reproductive success are positively correlated. Both earlier mating and reproductive success are enhanced by a larger repertoire in the European Starling (Sturnus vulgaris; Eens et al 1991). Other indicators of overall fitness such as size and age have also been linked to larger song repertoires in the Pied Flycatcher (Ficedula hypoleuca; Lampe and Espmark 1994) and Common Whitethroat (Sylvia communis; Balsby 2000). These observations have led many authors to conclude that females' selection for larger song repertoires is the main evolutionary factor driving repertoire size in species with large repertoires (Catchpole and Slater 2008). However, Byers and Kroodsma (2009) argued that the evidence does not support female choice as the primary driver of song complexity.

Two aspects of the organization of the Lark Sparrow's song appear to favor the proposal of Byers and Kroodsma (2009) that female preference for greater song diversity is not the key evolutionary factor driving the development of large repertoires. The lack of mixing of elements between the Lark Sparrow's themes reduces the potential song diversity below what could be achieved if all available elements were used interchangeably. Also, the fact that birds with multiple themes stayed with one theme for some time before switching to another (>20 strophes for MTRP_6-25-16, ML22963, XC416403, and XC416405) suggests that those birds were not trying reveal their full repertoire as quickly as possible. Byers and Kroodsma (2009) proposed an alternative hypothesis that large repertoires may be the result of the need for more complex messaging in a social context. Perhaps the Lark Sparrow's complex breeding behavior is somehow linked to a need for more complex vocal communication in this species.

Whether or not female selection is a factor in the evolution of the Lark Sparrow's song structure, the fact that Lark Sparrows have large repertoires and seem to follow a set of specific organizational rules with very little deviation (e. g., almost no mixing of elements between themes) suggests that repertoire size and adherence to these rules is important in the species' life history. Further studies with individually marked birds could reveal if factors such as the number of themes, size of the repertoire of elements, or adherence to organizational rules are correlated with age, fitness, or reproductive success.

\section{ACKNOWLEDGMENTS}

We thank all the recordists of the songs we used (W. Fish, G. Keller, B. Rideout, and R. Webster) as well as Xeno-Canto and the Macaulay Library for maintaining their extensive collections and making them available to us. Comments and suggestions from Kimball Garrett and two reviewers, Bruce Byers and Nathan Pieplow, helped to improve the clarity and thoroughness of the paper greatly.

\section{LITERATURE CITED}

Balsby, T. J. S. 2000. Song activity and variability in relation to male quality and female choice in Whitethroats Sylvia communis. J. Avian Biol. 31:56-62; doi 10.1034/j.1600-048X.2000.310108.x.

Baptista, L. F. 1975. Song dialects and demes in sedentary populations of the White-crowned Sparrow (Zonotrichia leucophrys nuttalli). Univ. Calif. Publ. Zool. 105:1-52. 
Beedy, E. C., and Pandolfino, E. R. 2013. Birds of the Sierra Nevada: Their Natural History, Status, and Distribution. Univ. Calif. Press, Berkeley.

Berger, A. J. 1968. Vesper Sparrow, in Life histories of North American cardinals, grosbeaks, buntings, towhees, finches, sparrows, and their allies (O. L. Austin, ed.), part 2, pp. 868-886. U.S. Natl. Mus. Bull. 237.

Borror, D. J. 1959. Songs of the Chipping Sparrow. Ohio J. Sci. 59:347-356.

Borror, D. J. 1961. Intraspecific variation in passerine bird songs. Wilson Bull. 73:57-78.

Borror, D. J. 1964. Songs of the thrushes (Turdidae), wrens (Troglodytidae), and mockingbirds (Mimidae) of eastern North America. Ohio J. Sci. 64:195-207.

Borror, D. J. 1965. Song variation in Maine Song Sparrows. Wilson Bull. 77:5-37.

Borror, D. J. 1971. Songs of Aimophila sparrows occurring in the United States. Wilson Bull. 83:132-151.

Byers, B. E., and Kroodsma, D. E. 2009. Female mate choice and songbird song repertoires. Anim. Behav. 77:13-22; doi 10.1016/j.anbehav.2008.10.003.

Carson, R. J., and Spicer, G. S. 2003. A phylogenetic analysis of the emberizid sparrows based on three mitochondrial genes. Molec. Phylogen. Evol. 29:43-57; doi:10.1016/S1055-7903(03)00110-6.

Catchpole. C. K. 1976. Temporal and sequential organization of song in the Sedge Warbler. Behaviour 59:226-246; doi 10.1163/156853976X00370.

Catchpole, C. K. 1980. Sexual selection and the evolution of complex songs among the warblers of the genus Acrocephalus. Behaviour 74:149-166; doi $10.1163 / 156853980 X 00366$.

Catchpole, C. K. 1986. Song repertoires and reproductive success in the Great Reed Warbler Acrocephalus arundinaceus. Behav. Ecol. Sociobiol. 19:439-445; doi 10.1007/BF00300547.

Catchpole, C. K., and Slater, P. J. B. 2008. Bird song: Biological Themes and Variations, 2nd ed. Cambridge Univ. Press, Cambridge, England; doi 10.1017/ CBO9780511754791.

Csárdi, G., and Nepusz, T. 2006. The igraph software package for complex network research. InterJournal, Complex Systems 1695.

Dunn, J. L., and Alderfer, J. A. 2017. National Geographic Field Guide to the Birds of North America. Natl. Geogr. Soc., Washington, D.C.

Eens, M., Pinxten, R., and Verheyen, R. F. 1991. Male song as a cue for mate choice in the European Starling. Behaviour 116:210-238; doi $10.1163 / 156853991 X 00049$.

Farnsworth, G., Londono, G. A., Martin, J. U., Derrickson, K. C., and Breitwisch, R. 2011. Northern Mockingbird (Mimus polyglottos), in The Birds of North America (A. F. Poole, ed,), no. 7, version 2.0. Cornell Lab Ornithol., Ithaca, NY; doi 10.2173/bna.7.

Grzybowski, J. A. 1995. Black-capped Vireo (Vireo atricapilla), in The Birds of North America (A. F. Poole and F. Gill, eds.), no. 181. Acad. Nat. Sci., Philadelphia; doi 10.2173/bna. 181.

Hedley, R. W. 2016. Composition and sequential organization of song repertoires in Cassin's Vireo (Vireo cassinii). J. Ornithol. 157:13-22; doi 10.1007/s10336015-1238-x.

Hiebert, S. M., Stoddard P. K., and Arcese, P. 1989. Repertoire size, territory acquisition and reproductive success in the Song Sparrow. Anim. Behav. 37:266-273; doi 10.1016/0003-3472(89)90115-2.

Hoffmann, R. 1927. Birds of the Pacific States. Riverside Press, Cambridge, MA.

Howard, R. D. 1974. The influence of sexual selection and interspecific competition on Mockingbird song (Mimus polyglottos). Evolution 28:428-438; doi $10.2307 / 2407164$. 
Krebs, J. R., Ashcroft, R., and Webber, M. 1978. Song repertoires and territory defense in the Great Tit. Nature 271:539-542; doi 10.1038/271539a0.

Kroodsma, D. E. 1972. Variations in songs of Vesper Sparrows in Oregon. Wilson Bull. 84:173-178.

Kroodsma, D. E. 1975. Song patterning in the Rock Wren. Condor 77:294-303; doi $10.2307 / 1366225$.

Kroodsma, D. 2005. The Singing Life of Birds. Houghton Mifflin, New York.

Lambrechts, M., and Dhondt, A. A. 1986. Male quality, reproduction, and survival in the Great Tit (Parus major). Behav. Ecol. Sociobiol. 19:57-63; doi 10.1007/ BF00303843.

Lampe, H. M., and Espmark, Y. O. 1994. Song structure reflects male quality in Pied Flycatchers Ficedula hypoleuca. Anim. Behav. 47:869-876; doi 10.1006/ anbe.1994.1118.

Lein, M. R. 1981. Display behavior of Ovenbirds (Seiurus aurocapillus) II. Song variation and singing behavior. Wilson Bull. 93:21-41.

Lemon, R. E., and Chatfield, C. 1973. Organization of song of Rose-breasted Grosbeaks. Anim. Behav. 21:28-44; doi 10.1016/S0003-3472(73)80037-5.

Martin, J. W., and Parrish, J. R. 2000. Lark Sparrow (Chondestes grammacus), in The Birds of North America (A. F. Poole and F. B. Gill, eds.), no. 488. Birds N. Am., Inc., Philadelphia; doi 10.2173/bna.488.

Patten, M. A., and Fugate, M. 1998. Systematic relationships among the emberizid sparrows. Auk 115:412-424; doi 10.2307/4089200.

Pieplow, N. 2017. Field Guide to Bird Sounds of Eastern North America. Houghton Mifflin, New York.

Pons, P., and Latapy, M. 2006. Computing communities in large networks using random walks. J. Graph Algorithms and Appl. 10:191-218; doi 10.7155/ jgaa.00124.

Potvin, D. A., Crawford, P. W., MacDougall-Shackleton, S. A., and MacDougallShackleton, E. A. 2015. Song repertoire size, not territory location, predicts reproductive success and territory tenure in a migratory songbird. Can. J. Zool. 93:627-633; doi 10.1139/cjz-2015-0039.

R Core Team. 2016. R: A language and environment for statistical computing. R Foundation, Vienna, Austria.

Sasahara, K., Cody, M. L., Cohen, D., and Taylor, C. E. 2012. Structural design principles of complex bird song: A network-based approach. PLoS One 7:e44436; doi 10.1371/journal.pone.0044436.

Shane, T. G. 2000. Lark Bunting (Calamospiza melanocorys), in The Birds of North America (A. F. Poole and F. B. Gill, eds.), no 542. Birds N. Am., Inc., Philadelphia; doi 10.2173/bna.542.

Sheppard, J. M. 2018. The biology of a desert apparition: LeConte's Thrasher (Toxostoma lecontei). Studies of Western Birds 2. W. Field Ornithol., Camarillo, CA.

Stillwell, J. E., and Stillwell, N. J. 1955. Notes on the songs of Lark Buntings. Wilson Bull. 67:138-139.

Todt, D., and Hultsch, H. 1998. How songbirds deal with large amounts of serial information: Retrieval rules suggest a hierarchical song memory. Biol. Cybernetics 79:487-500; doi 10.1007/s004220050498.

Watts, D. J., and Strogatz, S. H. 1998. Collective dynamics of "small-world" networks. Nature 393;440-442; doi 10.1038/30918.

Weiss M., Hultsch, H., Adam, I., Scharff, C., and Kipper, S. 2014. The use of network analysis to study complex animal communication systems: A study on Nightingale song. Proc. R. Soc. London B. 281:20140460; doi 10.1098/rspb.2014.0460.

Accepted 20 March 2019 